\title{
A escrita epistolar e autobiográfica em D'este viver aqui neste papel descripto: cartas da guerra, de António Lobo Antunes
}

Erivelto da Silva Reis Universidade Federal do Rio de Janeiro

Um homem se propõe a tarefa de desenhar o mundo. Ao longo dos anos, povoa um espaço com imagens de províncias, de reinos, de montanhas, de baías, de naus, de ilhas, de peixes, de moradas, de instrumentos, de astros, de cavalos e de pessoas. Pouco antes de morrer, descobre que esse paciente labirinto de linhas traça a imagem de seu próprio rosto.

Jorge Luis Borges

iteratura. História. Memória. Cada vez que se propõe a inter-relação entre estes três elementos na recente História de Portugal, sugere-se uma viagem pela experiência humana em aspectos que suprimem, de forma nítida e contundente, as diferenças supostas entre a Memória do real e a sua ficcionalização.

A ficção, na mímesis da realidade, pode se apropriar de passagens históricas, do ethos de pessoas anônimas e/ou figuras notórias, na busca pela representação verossímil de uma realidade inventada pela força da linguagem literária. Naturalmente, se a História e/ou as pessoas reais podem ser 
ficcionalizadas, como não supor que textos como cartas, diários e outros, considerados documentos, não possam ser o ponto de partida para a investigação de elementos narrativos e recorrências temáticas em obras de ficção para construir a ilusão de realidade em uma narrativa.

Em um contexto literário em que a ficção e a História se relacionam tão intimamente, o indivíduo que escreve passa a ser a "metonímia de uma nação" ou o testemunho de um momento específico apresentado pelo viés de um narradorpersonagem que, às vezes, identifica-se com o autor.

A História oficial passa a dever, pelo menos o benefício da dúvida - neste caso, traduzido em obrigação de se ler e refletir sobre o texto literário -, à ficcionalização da trajetória individual daqueles que lutaram e sobreviveram para escrever sobre o que testemunharam e resgataram, através da memória de si e dos outros, à custa da literatura, de documentos, de fotos, de correspondências e de diários do período vivenciado. $\mathrm{O}$ benefício da dúvida, inclusive, insere-se na investigação inerente às áreas do conhecimento que abordam, empiricamente, os mesmos temas.

Este artigo reflete sobre a construção epistolar da obra D'este viver aqui neste papel descripto: cartas da guerra (2005), que reúne a correspondência enviada por António Lobo Antunes à sua esposa, e busca detectar ou apontar a autobiografia evidenciada na escrita marcada pela presença do "eu", sujeito da enunciação na correspondência.

O objetivo deste artigo é analisar as cartas escritas do "campo de batalha", durante o período da Guerra Colonial em África, por um médico (combatente e participante de um batalhão operacional) à sua esposa. Tais cartas relatam o seu cotidiano, as suas emoções, as suas impressões, o seu testemunho e servem como verdadeiras declarações de amor à mulher amada. 
É importante destacar que, em um debate sobre o estatuto contemporâneo da biografia, Marília Rothier Cardoso e Pina Coco advertem-nos para o fato de que inerente a toda e qualquer "verdade", encontra-se a ficcionalização do vivido:

Dentre os diversos tipos de discursos, o literário é aquele em que a ficcionalidade da linguagem é explícita e serve de ponto de partida da composição, invalidando qualquer nexo simplificador entre as frases e seus eventuais referentes extralinguísticos. Nesse caso, o estudioso de literatura não se sentirá tentado a ler uma biografia como a "verdade" sobre um indivíduo real em sua (suposta) plenitude. Há muitas décadas que a teoria da literatura ensina que os relatos da vida ocupam o "não lugar" fabricado pelas estruturas linguísticas resultantes de séculos de tradição narrativa épica e romanesca. ${ }^{1}$

Assim, quando, alguns anos depois de ter estado no "campo de batalha", o jovem médico português, António Lobo Antunes inicia sua carreira literária, seus temas são a guerra, a solidão e o choque que a morte produz nos homens e nas sociedades. Seus romances, embora se baseiem em dados considerados factuais e verídicos, buscam, ficcionalmente, discutir como a sociedade portuguesa foi conduzida à guerra, como se comportou durante o período e como se reorganizará após o fim do conflito.

Os romances iniciais de Lobo Antunes (e referimo-nos a Memória de Elefante, Os Cus de Judas e Conhecimento do inferno) relatam situações vividas por seus narradores-personagens, autores, aparentemente, de relatos pseudo-autobiográficos, resultantes da estada em África ou da vivência em Lisboa após o trauma sofrido no exílio.

${ }^{1}$ CARDOSO; COCO, 2003, p. 7. 
A barbárie, o horror da morte, a crítica direta ou velada ao sistema e às instituições e o contato com o outro e com o que este representa como indivíduo ou como inimigo portador de ideologia e cultura diferentes são tematizados. Os romances surgem como um espelho, capaz de retratar o estranhamento e de refletir sobre os desmandos da política expansionista portuguesa.

Espera-se, assim, ao longo deste artigo, demonstrar que António Lobo Antunes, ao ficcionalizar a sua trajetória como médico, a serviço do exército português na Guerra Colonial em África, já prenuncia, através das "Cartas da Guerra", elementos que serão retomados em suas narrativas posteriores, principalmente, em Os Cus de Judas (1979).

Nota-se que no romance Os Cus de Judas, a trajetória ficcional do narrador-personagem, o "eu" da enunciação, mescla-se à figura do autor e de sua autobiografia, diluída em frases, reflexões e situações narradas referentes às passagens da História.

Em alguns romances posteriores, de maneira direta pelo viés da autoficção, como, por exemplo, em Sôbolos rios que vão, torna-se, ele mesmo, personagem de seus romances. Em outros, resgata memórias, inventa outras, busca solucionar, através da ficção, o que a vida construiu sem resposta (aparente/aceitável), sem volta, sem saída.

Não nos esqueçamos de que a memória consagra as lembranças, a história evoca os vultos; a memória registra impressões, a história elenca fatos; a memória embaralha passagens, a história sinaliza as datas; a memória busca personae, a história congrega os nomes; a memória é lúdica, a história é cronológica; a memória motiva, a história impulsiona; a memória é literária, a história codifica; a memória simboliza, a história significa. Tal como se fossem faces da mesma moeda, porém, com valores díspares.

A trajetória de Lobo Antunes revela a marca daqueles que passam pelo mundo e que produzem algo que ateste a sua 
presença: um livro, um filho, uma autobiografia, o engajar-se na luta por seu país ou o encontrar um determinado amor. É a dinâmica das relações humanas. É o destino dos que escrevem, é o destino dos que vivem e sonham. "Todas as cartas de amor são ridículas", escreveu Fernando Pessoa. E, sob a égide do grande bardo português, nos seria possível questionar se todas as cartas de amor e de guerra não poderiam ser, também, autobiográficas e históricas?

Assim, justifica-se a pesquisa que deu origem a este artigo: considerar o recurso da investigação de documentos da época da Guerra Colonial em África, especificamente, a correspondência escrita pelo médico António Lobo Antunes à sua esposa, como objetos característicos de uma escrita autobiográfica e epistolar que podem servir como uma espécie de pacto de veracidade na inter-relação entre a ficção e a História de Portugal, durante este período. Pretende-se considerar, inclusive, a memória e a autobiografia do autor como elementos associados às características de seus narradores-personagens das obras iniciais e, sobretudo, como elementos que justificam a recorrência temática em seus romances.

António Lobo Antunes é um notável expoente da ficção portuguesa contemporânea, um dos autores portugueses mais conhecidos e mais lidos em todo o mundo, autor de, pelo menos, duas dezenas de romances considerados como grandes obras literárias; premiado e reconhecido internacionalmente, é um dos cânones da nova ficção portuguesa que propõe, ao longo das últimas três décadas, uma profunda reflexão sobre a história recente de Portugal e seus desdobramentos na organização cultural, política e social do país e sobre seu reposicionamento na nova ordem mundial.

São temas recorrentes nos romances do autor a guerra, a solidão, a reconstrução do passado por uma memória fragmentada (a própria narrativa antuniana se constrói sobre a 
égide da fragmentação e do fluxo de consciência), o trauma da guerra, o exílio e a condição humana, marcada pela ausência de pertencimento e pelo isolamento, diante das transformações sociais e da incapacidade de interação com o outro.

Seus personagens emergem das trincheiras de guerra, do horror letárgico de memórias traumatizantes, de relatos sombrios e confusos sobre a própria identidade e refletem as dificuldades em se fazer compreender pelos outros e de incorporar, novamente, os parâmetros sociais estabelecidos, após a experiência do exílio, da repressão salazarista e da morte pressentida.

Seus narradores e personagens constituem-se, literal e metaforicamente, em uma prosa repleta de elementos que se aproximam do poético, para narrar o que pode ser torpe, vil ecruel e o que ressignifica e transfigura a percepção de objetos, épocas, sentimentos e pessoas que se reconstroem pela maneira de narrar.

Misturam-se, na obra antuniana, os tempos cronológico e psicológico e o pano de fundo é a história particular real ou inventada de narradores e personagens sobreposta à recente História de Portugal.

A memória expurga e alimenta a narrativa. Coaduna-se com fatos verificáveis como reais e/ou verossímeis, traz à tona elementos novos, conhecidos in loco, através da vivência ou das experiências do autor que as reordena, corrige e exacerba, a fim de produzir uma catarse, ao experimentar uma purgação das emoções, através da representação ficcional do real.

O problema que se pretende discutir diz respeito à verificação de que as cartas escritas por Lobo Antunes, durante o seu período como médico a serviço do exército português, poderiam se configurar como uma espécie de pacto autobiográfico, tal procedimento estende-se a seus narradores e personagens e à recorrência temática, presentes nos romances iniciais antunianos, no que concerne à guerra, à solidão e à 
construção narrativa fragmentada por memórias agudas e doloridas de um passado recente.

Em suma, pretende-se constatar se haveria sobreposição entre a figura elocucionária do autor, que esteve no "campo de batalha" (fato verificável pela história pessoal do autor e corroborado pela análise de suas cartas) e a estruturação de seus narradores e personagens.

A hipótese que norteia este artigo é a de que seria possível, em face do estudo da biografia e das cartas do autor, localizá-lo e às suas experiências ou vivências apreendidas, durante o período citado, seja no âmbito da História, seja no âmbito do Espaço, representado como ficção, em suas obras iniciais. A Memória desses acontecimentos possibilita, assim, ao autor encontrar subsídios de representação temática para seus romances.

Leia-se o professor Alcir Pécora, no texto "Velhos textos, crítica viva", escrito como apresentação à obra $A$ arte de escrever cartas: Anônimo de Bolonha, Erasmo de Rotterdam, Justo Lípsio (2005), organizada por Emerson Tin:

Levantar legibilidade de objetos antigos para ampliar o vocabulário crítico do presente: eis o que me parece ser um programa de estudos de excelência. [...] pode, perfeitamente, significar hipóteses criativas para a interpretação de objetos contemporâneos: da carta oficial até o e-mail. O levantamento em jogo aqui, longe de mumificar objetos culturais, quer testar hipóteses para escrituras do presente ainda inexploradas pelos lugares-comuns da crítica e da leitura. ${ }^{2}$

Entende-se, como hipótese, que a escrita das cartas e o conteúdo autobiográfico que elas possuem são um elo capaz de coadunar e ampliar a percepção da inter-relação entre a

2 PECORA, 2005, p. 13; 15. 
Memória, a História e a Ficção na obra de António Lobo Antunes. É importante destacar que a epistolografia é o estudo da escrita de cartas entre indivíduos e/ou grupos distantes ou separados contextualmente e que a estruturação da narrativa ficcional, através da simulação, do envio ou da troca de correspondência entre personagens, torna-se, aqui uma característica da narrativa antuniana, embora não tenhamos acesso às cartas escritas pela esposa, Maria José Xavier da Fonseca e Costa Lobo Antunes.

Lembremo-nos de que nos séculos XVIII e XIX, diversos autores utilizavam-se do recurso ficcional no qual um narrador, ao explicar que encontrou um diário ou um conjunto de cartas sobre determinado personagem, buscava tornar credível o que narrava. Outros, por sua vez, ao estruturar capítulos ou trechos de suas obras, sob a forma do gênero epistolar, assumiam a sua autoria ou reproduziam, ao longo dos capítulos, cartas e páginas de diários inventados.

A antologia de cartas elencadas em $D^{\prime}$ este viver aqui neste papel descripto: cartas da guerra (2005), é um conjunto de cartas reais, enviadas por um homem, um médico, direto do "campo de batalha" para a sua amada - muito amada - esposa com a qual recentemente se casara e de quem se despedira, temporariamente, ao ser incorporado ao exército (durante o regime fascista e salazarista português), deixando-a grávida da primeira filha do casal.

O fato de esse médico vir a se tornar um dos autores mais consagrados e lidos, nos séculos XX e XXI, na literatura portuguesa e possuir, em sua lista de romances, títulos que demonstram a recorrência dos temas da guerra e da memória, decorrentes, possivelmente, de uma experiência pessoal, suscita a necessidade de uma leitura crítica dessa correspondência.

Não se pretende, portanto, argumentar sobre a configuração de uma possível literatura epistolar recorrente na obra antuniana ou, ainda, apontar para a produção contundente, indiscutível e 
direta de uma autobiografia. Entende-se, igualmente, que as experiências autobiográficas contidas nas "Cartas da Guerra" (marcas de uma trajetória pessoal), predispõem o leitor à superposição entre a figura do autor e a de seus narradorespersonagens em narrativas que tenham como tema a Guerra Colonial em África ou a ela se refiram.

As cartas de Lobo Antunes à esposa permitem aos leitores participarem de uma história de enlevo e de amor demonstrados, em plenitude e desassossego, em suas missivas, através de uma escrita intensa e contínua, que faz, também, com que se sintam desterrados e exilados, por saberem-nas escritas no contexto histórico da guerra. Por servirem como lastro para a análise do que poderia ser considerado um importante processo na gênese da obra antuniana.

A Guerra Colonial ou Guerra do Ultramar inicia-se nos primeiros meses do ano de 1961. Para os africanos, ficaria conhecida como Guerra de Libertação Nacional. Os conflitos entre portugueses e africanos iniciados nessa data irão durar até o histórico dia 25 de abril de 1974, quando ocorre a Revolução dos Cravos.

As cartas escritas por António Lobo Antunes compreendem um conjunto bastante peculiar e atraente ao exercício da investigação do processo de escrita do autor. Seja porque a subjetividade e o testemunho serão recorrentes nos primeiros romances do autor, seja porque dão a conhecer diversos aspectos vistos e vivenciados pelo autor e reconfigurados em seus romances.

As cartas interessam, sobremaneira, por registrarem o trauma de um regime de exceção vivido/testemunhado por Lobo Antunes, o exílio forçado para servir ao exército português e o fato de se aproximarem do narrador-personagem de suas obras iniciais.

Entende-se, portanto, que, além de documentarem um período da recente História de Portugal, servem como base 
para se observar a estruturação de uma escrita autobiográfica que permitirá que os leitores dos romances de Lobo Antunes possam considerar a sua escrita não apenas como fruto de uma produção literária focalizada em um período histórico, mas como fruto de sua vivência, como parte de sua trajetória pessoal, como elementos possivelmente resgatados de sua memória.

Por epistolografia, entende-se o conjunto de cartas escritas e/ou enviadas e/ou textos ficcionais produzidos a partir da estrutura de uma carta. O estudo desse gênero ou das produções híbridas que dele se apropriem constitui cada vez mais um manancial de pesquisa na literatura contemporânea, sobretudo quando os romances ou as cartas se aproximam de temas que evocam a ficcionalização da história através da memória de autores (motivação da produção das obras) e personagens e narradores. Assim, busca-se estabelecer um pacto de veracidade através da construção de uma escrita testemunhal e/ou autobiográfica.

As cartas, os diários, as escritas do "eu", de um modo geral, são estratégias narrativas e álibis da verossimilhança verificadas na literatura portuguesa, pelo menos, desde o século XVIII. Ao aproximar a sua experiência pessoal das ações de seus narradores e personagens, Lobo Antunes mostra-se e indica como vê o processo. Finge-se de personagem para espelhar-se como pessoa. Resolve como personagem, ou expurga a memória de conflitos e sentimentos não resolvidos como sujeito.

Além disso, sabemos que o processo associativo de ideias pode levar o leitor a ligar, diretamente, autor e fato narrado no texto, considerando, parcialmente, aspectos semióticos do hibridismo do gênero narrativo-discursivo que são inerentes à estruturação textual e referentes às instâncias narrativas, a partir da mescla das funções de linguagem, o que permitiria a legitimação da memória e da sua interioridade e dos aspectos 
autobiográficos e subjetivos presentes ou percebidos como presentes na organização narrativa dos romances.

Nas "Cartas da Guerra", Lobo Antunes, nitidamente, encontra-se no cenário que virá a ser retratado em alguns de seus romances. Suas cartas, na perspectiva do tempo em que foram escritas, são depoimentos, registro de atividades, declarações hiperbólicas de amor. Hoje, sob nosso ponto de vista, podem ser lidas como documento. Memória escrita palpável de elementos que permeiam a História de Portugal, a trajetória pessoal do autor e a tessitura narrativa de alguns de seus romances.

Pode-se discutir, até mesmo, os elementos narrativos de representação ficcional do autor pelos conteúdos que já, a esta altura, estão presentes nas cartas e que não são ficção. Leia-se um trecho da $7^{\mathrm{a}}$ carta enviada por Lobo Antunes:

\subsubsection{1}

Minha namorada querida

Aqui cheguei finalmente a Gago Coutinho, depois de uma viagem apocalíptica, como nunca pensei ter de fazer em qualquer época da minha vida. [...] Isto é o fim do mundo: pântanos e areia. A pior zona de guerra de Angola: 126 baixas no batalhão que rendemos, embora apenas com dois mortos, mas com amputações várias. Minas por todo o lado. [...]. ${ }^{3}$

Ou ainda, a percepção do outro, do colonizado. A quebra do estigma através da real percepção de como aquele que é tido como exótico (o que se vê apenas do ponto de vista externo, exterior). Leia-se um fragmento da $106^{\text {a }}$ carta de Lobo Antunes à esposa:

${ }^{3}$ LOBO ANTUNES e LOBO ANTUNES, 2005, p. 27; 29. 


\section{6 .71}

Minha alma querida

Aqui estou, nervoso, à tua espera: é dia de cartas, de notícias, de ternas palavras de amor. [...] E recomeço a passear na areia de mãos nos bolsos. [...] Tudo aqui parece inalterável: nenhuma nuvem, e um tempo desagradavelmente ventoso. Talvez por estarmos num alto, numa espécie de pequeno morro. Ao longe vê-se a imensa chana do Quango. QuangoCubango. Pegado ao arame um quimbo de 70 habitantes. $\mathrm{O}$ soba, que fala bastante bem português, é um nacionalista feroz. [...] Quase todos os habitantes têm alcunhas postas pela tropa. ${ }^{4}$

Enquanto espera pelas cartas da esposa, Lobo Antunes percebe que a relação entre os soldados e os habitantes dos lugarejos pelos quais a tropa vai passando em Angola se dá, ora pelo confronto, mutilação e morte de rebeldes e soldados, ora pela postura de subserviência dos angolanos para com os portugueses.

O autor ainda revela na carta que os africanos são apelidados conforme suas compleições físicas e pela maneira como suas características e personalidade são notadas pelos soldados e oficiais da tropa. Ao escrever sobre isso, vale-se, inclusive, de palavras e expressões na língua dos nativos, a fim de demonstrar, possivelmente, o "domínio" de algumas dessas expressões e a sua percepção do exotismo da língua e do povo angolano.

Se o equilíbrio entre a verossimilhança e a verdade já se tornara complexo e fragilizado pela necessidade humana de contar e pela necessidade literária de narrar, imagine-se o embate entre esses paradigmas quando o próprio autor sente necessidade ou pretenda narrar algo que ele mesmo tenha vivenciado.

${ }^{4}$ LOBO ANTUNES e LOBO ANTUNES, 2005, p. 183-184. 
Como já dito, D'este viver aqui neste papel descripto: cartas da guerra (2005) é a reunião de cartas escritas por António Lobo Antunes quando este contava 28 anos. Foram escritas durante dois anos, no início da década de 1970, com três breves interrupções. O título da obra batizaria/nomearia o primeiro romance publicado por Lobo Antunes, porém, o título inicialmente atribuído, Memória de Elefante, é recusado pela editora.

As "Cartas da Guerra" (2005), escritas por António Lobo Antunes, perfazem, aproximadamente, 300 cartas; boa parte delas, aerogramas (correspondência própria da comunicação escrita entre militares e seus familiares, em situação de serviço, e que não precisavam de selo para seu envio).

A publicação desse material epistolar foi possibilitada, em grande parte, pelo trabalho cuidadoso e, acredita-se, devotado, das organizadoras, filhas do casal, ao selecionar as cartas e os documentos que compõem o volume. Leia-se um trecho da apresentação da coletânea escrito por Maria Josée Joana Lobo Antunes:

As cartas que aqui se leem são transcrições integrais dos originais, apenas com a correção de gralhas e actualização ortográfica. Decidimos eliminar alguns nomes, usando letras que não as iniciais, para não ferir susceptibilidades das pessoas referidas e de suas famílias. [...] Julgamos que o interesse destas cartas vai muito além da identificação de todas as citações, poemas, livros e autores de que nelas se fala, e damos espaço ao leitor para as descobrir se assim entender. [...] Este é o livro do amor dos nossos pais, de onde nascemos e do qual nos orgulhamos. Nascemos de duas pessoas invulgares em tudo, que em parte vos damos a conhecer nestas cartas. O resto é nosso. [...]

Maria José Lobo Antunes

Joana Lobo Antunes

Lisboa, Março de $2005^{5}$

${ }^{5}$ LOBO ANTUNES e LOBO ANTUNES, 2005, p. 12-13. 
Observa-se que a organização das "Cartas da Guerra", ao longo das 431 páginas da obra, constitui um espaço propício para o pacto autobiográfico, - "este é o livro do amor de nossos pais" -, somado ao material (fotos e documentos) que vai compor eilustrar sua leitura, além, naturalmente, das claras informações sobre as datas de cada carta (quase um "diário de guerra", em alguns períodos) e a indicação geográfica presente nas cartas contribuirá para atestar a sua veracidade.

Observe-se, a seguir, será reproduzida uma carta bastante peculiar em estrutura e conteúdo. Leia-se a $70^{\mathrm{a}}$ carta:

\subsubsection{1}

Meu amor querido

Adoro-te minha gata de Janeiro meu amor minha gazela meu miosótis minha estrela aldebaran minha amante minha Via Láctea minha filha minha mãe minha esposa minha margarida meu gerânio minha princesa aristocrática minha preta minha branca minha chinezinha minha Paulina Bonaparte minha história de fadas minha Ariana minha heroína de Racine minha ternura meu gosto de luar meu Paris minha fita de cor meu vício secreto minha torre de andorinhas três horas manhã minha melancolia minha polpa de fruto meu diamante meu sol meu copo de água minhas Escadinhas da Saudade minha morfina ópio cocaína minha ferida aberta minha extensão polar minha floresta meu fogo minha única alegria minha América e meu Brasil minha vela acesa minha candeia minha casa meu lugar habitável minha mesa posta minha toalha de linho minha cobra minha figura de andor meu anjo de Boticelli meu mar meu feriado meu domingo de Ramos meu setembro de vindimas meu moinho no monte meu vento norte meu sábado à noite meu diário minha história de quadradinhos meu recife de Manuel Bandeira minha Passargada meu templo grego minha colina meu verso de Hölderlin meu gerânio meus olhos grandes de noite minha linda boca macia dupla como uma concha 
fechada meus seios suaves e carnudos meu enxuto ventre liso minhas pernas nervosas minhas unhas polidas meu longo pescoço vivo e ágil minhas palavras segredadas meu vaso etrusco minha sala de castelo espelhada meu jardim minha excitação de risos minha doce forquilha de coxas minha eterna adolescente minha pedra brunida meu pássaro no mais alto ramo da tarde meu voo de asas minha ânfora meu pão de ló minha estrada minha praia de Agosto minha luz caiada meu muro meu soluço de fonte meu lago minha Penélope meu jovem rio selvagem meu crepúsculo minha aurora entre ruínas minha Grécia minha maré cheia minha muralha contra as ondas meu véu de noiva minha cintura meu pequenino queixo zangado minha transparência de tules minha taça de oiro minha Ofélia meu lírio meu perfume de terra meu corpo gémeo meu navio de partir minha cidade meus dentes ferozmente brancos minhas mãos sombrias minha torre de Belém meu Nilo meu Ganges meu templo hindu minha areia entre os dedos minha aurora minha arpa meu arbusto de sons meu país minha ilha minha porta para o mar meu mangerico, eu cravo de papel minha Mandragoa minha morte de amor minha Ana Karénine minha lâmpada de aladino minha mulher. ${ }^{6}$

Nesta carta, composta por 406 palavras escritas sem um único ponto ou vírgula, expõe-se a ideia de possuir e de ser possuído não apenas pelo amor, mas de possuir o ser que sente amor. É uma carta estruturada através de metáforas que dimensionam, (hiperbolicamente), do mais íntimo e cotidiano da vida do casal, até a comparação com imagens, locais, personagens, plantas, animais, minerais, sentimentos, formas e sensações, passado e presente. Tende a apresentar a ideia de completude. Como se na ausência do ser amado, o amor completasse aquele que o sente e atingisse o ápice de seus significados possíveis.

${ }^{6}$ LOBO ANTUNES e LOBO ANTUNES, 2005, p. 131-132. 
Em correspondência enviada a 27.2.71 - a $27^{\mathrm{a}}$ carta - Lobo Antunes escreve: "Li numa revista [...] que a Editora Inova [...] publicou as poesias completas de Ângelo de Lima que muito gostaria de ter e ler por se tratar de uma das minhas preferências desde sempre.".

O título da obra D'este viver aqui neste papel descripto é a citação de um verso escrito pelo poeta Ângelo de Lima (1872-1921) ao Prof. Miguel Bombarda. Esta referência encontra-se na página 237 na $143^{\text {a }}$ carta escrita por Lobo Antunes:

\section{7 .71}

Minha querida joia

Mais uma longa e triste segunda-feira, "deste viver aqui neste papel descripto", como o Ângelo de Lima diz numa carta ao dr. Miguel Bombarda. Deste viver aqui neste papel descripto. [...] Entretanto a história parece definitivamente empanada. Raios a partam - mas que posso eu fazer? Que bonito é "deste viver aqui neste papel descripto"! !

O poeta Ângelo de Lima, que passou vários anos de sua vida internado em hospitais psiquiátricos, deu origem a um estudo clínico efetuado por Lobo Antunes. Este estudo, escrito em parceria com Maria Inês Dias (Ângelo de Lima: Loucura e criação artística: Ângelo de Lima, poeta de Orpheu) em 1974, ganhou o Prêmio Sandoz de Psiquiatria neste mesmo ano.

Curiosamente, o nome do Prof. Miguel Bombarda daria nome ao Hospital no qual Lobo Antunes viria a trabalhar em 1973. Leia-se Maria José Lobo Antunes e Joana Lobo Antunes no prefácio da obra:

${ }^{7}$ LOBO ANTUNES e LOBO ANTUNES, 2005, p. 237. 
As cartas deste livro foram escritas por um homem de 28 anos na privacidade de sua relação com a mulher, isolado de tudo e de todos durante dois anos de Guerra Colonial em Angola, sem pensar que algum dia viriam a ser lidas por mais alguém. Não vamos aqui descrever o que são estas cartas: cada pessoa irá lê-las de forma diferente, seguramente distinta da nossa. Mas qualquer que seja a abordagem, literária, biográfica, documento de guerra ou história de amor, sabemos que é extraordinária em todos os aspectos. [...] A escolha de as publicar não é nossa: é a vontade expressa de nossa Mãe, destinatária e conservadora deste espólio até há pouco tempo. Sempre nos disse que as poderíamos ler e publicar depois de sua morte, e esse momento chegou agora. ${ }^{8}$

A correspondência inicia-se em 07.01.1971 e encerra-se em 30.01.1973. Seu conteúdo relata a saudade de António Lobo Antunes, suas leituras (romances e poemas), as influências culturais, o nascimento da filha (Maria José), os lugares pelos quais vai passando, na geografia do exílio: Ilha da Madeira, Luanda, Gago Coutinho, Chiúme, Ninda (as Terras do fim do mundo) e Marimba.

Dessa forma, deve-se observar a importância da função que a ética, a literatura e a arte têm no processo de estabelecer o respeito à pluralidade cultural, ao reconhecimento de processos culturais e religiosos diferentes e coexistentes. A diferença entre culturas e paradigmas não deve representar antagonismos e se traduzir em guerras e em mortes.

${ }^{8}$ LOBO ANTUNES e LOBO ANTUNES, 2005, p. 12. 


\section{Referências}

ANTUNES, António Lobo. Os Cus de Judas. 2. ed. Rio de Janeiro: Objetiva, 2007.

ANTUNES, António Lobo. D'este viver aqui neste papel descripto: cartas da guerra. In: ANTUNES, Maria José Lobo; Joana Lobo (Org.). Lisboa: Dom Quixote, 2005.

BORGES, Jorge Luis. Obras completas. Trad. Carlos Nejar. Rio de Janeiro: Globo, 1998. V. I.

CARDOSO, Marília Rothier; COCO, Pina. Apresentação: perspectivas (auto) biográficas nos estudos de literatura. Palavra, Rio de Janeiro, Departamento de Letras da PUC-Rio: Editora Trarepa, n. 10, 2003.

DUQUE-ESTRADA, Elizabeth Muylaert. Devires autobiográficos: a atualidade da escrita de si. Rio de Janeiro: NAU/Editora PUC-Rio, 2009.

LEJEUNE, Philippe. O pacto autobiográfico: de Rousseau à Internet. Jovita Maria Gerheim Noronha (Org.). Trad. Jovita Maria Gerheim Noronha e Maria Inês Coimbra Guedes. Belo Horizonte: UFMG, 2008. (Série: Humanitas).

PÉCORA, Alcir. Velhos textos, crítica viva. In: TIN, Emerson (Org.). A arte de escrever cartas: Anônimo de Bolonha, Erasmo de Rotterdam, Justo Lípsio. Campinas: Editora da Unicamp, 2005.

SEIXO, Maria Alzira. Autobiografia. In: - Os romances de António Lobo Antunes: análise, interpretação, resumos e guiões de leitura. Lisboa: Dom Quixote, 2002.

SEIXO, Maria Alzira. As Flores do inferno e jardins suspensos: Vol. II de Os romances de António Lobo Antunes. Lisboa: Publicações Dom Quixote, 2010. 


\section{Resumo}

O presente artigo é um estudo acerca das características epistolares e autobiográficas presentes na obra $D^{\prime}$ este viver aqui neste papel descripto: cartas da guerra (2005), de autoria de António Lobo Antunes, organizada pelas filhas do autor, Maria José e Joana Lobo Antunes, após a morte de sua mãe. A partir das reflexões críticas presentes em $O$ pacto autobiográfico: de Rousseau à Internet (2008), de Philippe Lejeune, Devires autobiográficos: a atualidade da escrita de si (2009), de Elizabeth Muylaert Duque-Estrada e Os romances de António Lobo Antunes: análise, interpretação, resumos e guiões de leitura (2002) de Maria Alzira Seixo, busca-se demonstrar como a experiência real do exílio e o horror da guerra encontram ecos na obra antuniana, e apontar as relações entre história, memória e ficção.

\section{Abstract}

This article is a study of the characteristics present in the epistolary and autobiographical work D'este viver aqui neste papel descripto: cartas da guerra (2005), written by Antonio Lobo Antunes, organized by the author's daughters, Maria Jose and Joanna Lobo Antunes after the death of his mother. 
